\title{
Design of Off-grid Home Photovoltaic Power System in Shaanxi Region
}

\author{
Ke Cheng, Jie Yang, Yan Chen \\ School of Power and Energy, Northwestern Polytechnical University, Xi'an, P. R. China \\ Email: cksolar@sohu.com
}

Received February, 2013

\begin{abstract}
Shaanxi province has three land forms which are Shaanxi's northern plateau, Guanzhong plain and Qinba mountain land in the south of Shaanxi province. So the climate type is also divided into three types and the solar energy resources distribution has a big gap between different regions. PV modules, as the core component of off-grid home photovoltaic power system, their output power are mainly influenced by sun radiation, array tile angle, temperature and so on. Based on the reasons above, in order to apply off-grid home photovoltaic power system in Shaanxi region, this paper designs different systems with different configuration, and makes the performance prediction. The results show that the capacity of PV modules reaches to the largest in Shaanxi northern region, reach minimum in Shaanxi southern region and the output power in the winter is less than in the summer and reach minimum in the spring and autumn. In light of the characteristics above, this research select different type and configuration in different areas systematically, and the performance analysis shows that the configuration can meet the basic life demand of power to the people whose power is not available.
\end{abstract}

Keywords: Solar; Photovoltaic Power Generation; Off-grid Home Photovoltaic Power System

\section{Introduction}

It is about 870 kilometers from Shaanxi northern to Shaanxi southern. Shaanxi province has three landforms which are Shaanxi northern plateau, Guanzhong plain and Qinba mountain land in south of Shaanxi. So climate type is also divided into three types. Shaanxi northern region belongs to warm temperate zone arid and semiarid climate. Guanzhong belongs to warm temperate zone semi-humid climate and Shaanxi southern region belongs to north subtropical humid climate. In this case, the distribution of solar energy resource has a big gap in different regions, especially between north and south in Shaanxi province, the annual total sunshine radiation is $3830-5750 \mathrm{MJ} / \mathrm{m}^{2}$, the annual sunshine hours is 1270 2900 hours and sunshine percentage is $28 \%-64 \%$.

Off-grid home photovoltaic power system mainly consists of PV modules, batteries, controller and inverter. Among them PV module is the core component that makes sun radiant energy into electricity. Power system's capacity is mainly influence by the sun radiation, array tile angle, temperature and other factors[1-2].

For example, the output power of crystalline silicon PV modules in proportion to the accepted sun radiation intensity, power generation efficiency is inversely proportional to the temperature. Based on the above reasons, in order to apply off-grid home photovoltaic power sys- tem in Shaanxi region, this paper designs different system with different configuration, and makes the performance prediction.

\section{Resource Condition}

In Shaanxi province the annual total solar radiation is in a high level, solar energy total reserve is $2.71 \times 1015$ $\mathrm{kWh}$, ranking eleventh in China. The distribution characteristics are the radiation in the north is more than in the south. There is a great gap between north and south. High value areas are located in the Shaanxi northern along the Great Wall area and the east area of the north of Weishui, and low value areas are mainly distributed in Shaanxi southern[3].

According to annual total solar radiation, the solar energy resources of Shaanxi province can be divided into three areas: the area with very adequate solar resources, including Shaanxi northern; the area with adequate solar resources, including the south of Shaanxi northern, Guanzhong region, the northeast of Shangluo and Ankang in Shaanxi southern; the area with relatively adequate solar energy resources, including most areas of Hanzhong and Ankang in Shaanxi southern. Sunshine hours and sunshine percentage in Shaanxi are show in Figures 1 and 2.

In the four seasons, total radiation can reach maximum in the summer accounting for $35 \%$ of the annual total 
radiation. In the summer around north of Shaanxi northern area and east area of northern Weishui the total solar radiation reach high value. In the winter total radiation reaches minimum and accounts for $16 \%$ of the annual total radiation.

\section{Electricity Load}

Reference to investigation in other areas, kerosene lamp, candles, fire and flashlight are the first choice to illuminate when photovoltaic power generation is not available, and TV, VCD, DVD and other appliances cannot use then. After photovoltaic power generation is available, lamp become the main lighting equipment, the use of household electric appliances, such as TV, tape recorder has a significant upward trend.

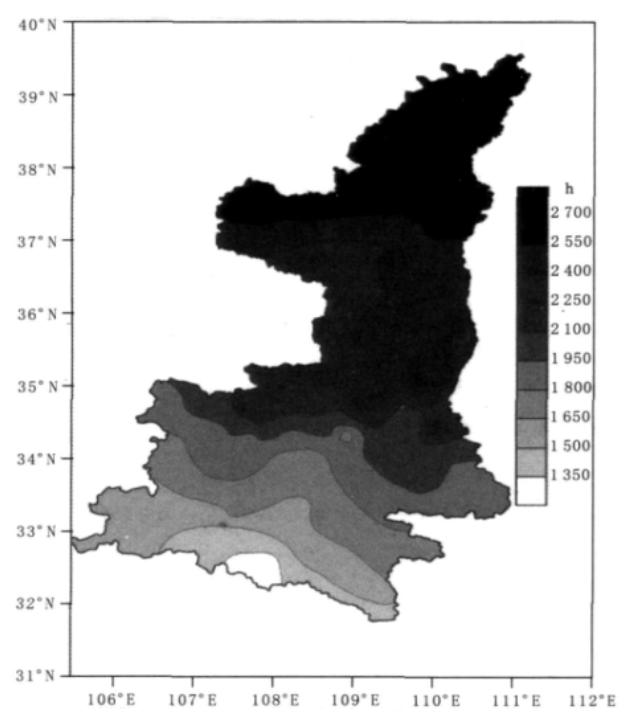

Figure 1. Sunshine hours in Shaanxi Province.

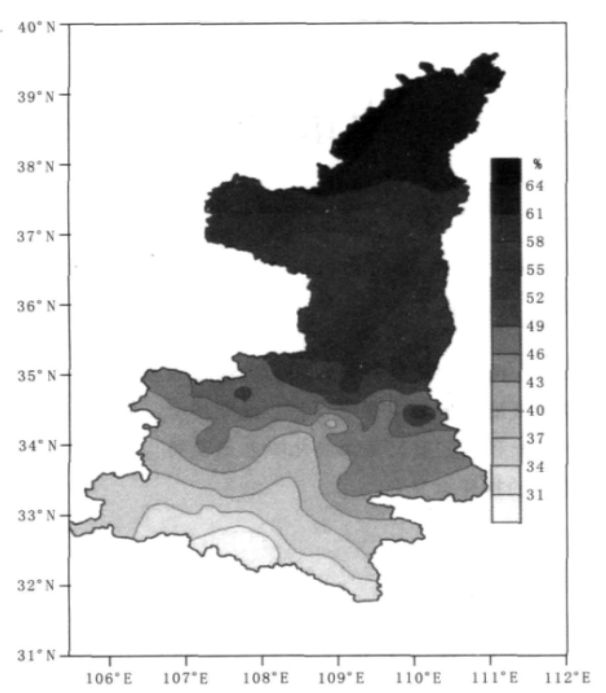

Figure 2. Sunshine percentage in Shaanxi Province.
Design load according to TV is $70 \mathrm{w}$, light is $30 \mathrm{w}$, the basic living power can be contented. Electricity time is 4 hours, power peak is around $100 \mathrm{~W}$, average load is around $80 \mathrm{~W}$.

\section{Design Selection}

\subsection{Principle of Photovoltaic Power Generation}

The solar cell of photovoltaic power generation is $p-n$ junction which is surface contact type. When there is no light, it is equivalent to a diode. Otherwise the voltage between the two sides of solar cell gets just make p-n junction forward bias. The ideal equivalent power model is a constant current source in parallel a diode. The ideal $\mathrm{I}-\mathrm{V}$ characteristic is:

$$
I=I_{L}-I_{0}\left[\exp \left(\frac{q V}{n k T}\right)-1\right]
$$

$\mathrm{I}_{\mathrm{L}}$ - photo current

$\mathrm{I}_{0}$ - saturation current of diode

q- charge quantity of electronic

k- Boltzmann constant

T- absolute temperature(K)

The output power is the product of current and voltage. It can be show use formula (2):

$$
P=I V=I_{L} V-I_{0} V\left[\exp \left(\frac{q V}{n k T}\right)-1\right]
$$

\subsection{Design Calculation}

It has shown the solar energy resources in eight cities of Shaanxi in Figure 3. In order to facilitate selection, placed $100 \mathrm{Wp}$ monocrystal silicon components use local latitude as it's tilt angle and simulate to calculate the PV module's theoretical monthly output power, and the results show in Figure 4.

The results show that the output power in the winter is less than in the summer for the synthesis influence of local solar radiation and ambient temperature. Because the power generation efficiency of PV modules is inversely proportional to the temperature, when the temperature rise every $1{ }^{\circ} \mathrm{C}$, the efficiency drop about $0.5 \%$.

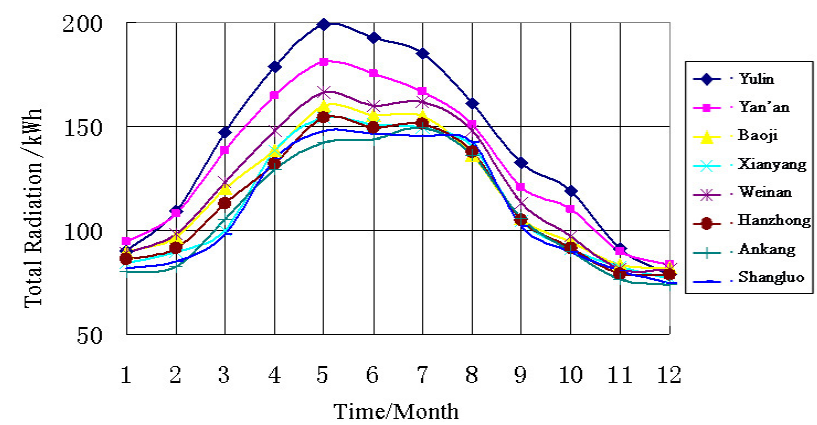

Figure 3. Global solar radiation in Shaanxi Province. 
So in September and October, the output power reaches minimum generally. Especially in Yulin and Yanan although solar radiation is weak in the winter, output power is more than in the summer for the environment temperature is below zero.

\subsection{Configuration Selection}

According to the power load and PV module products series, the results are shown as in Table $\mathbf{1 .}$

\section{Performance Analysis}

According to the configuration in Table $\mathbf{1}$ and the local meteorological data, predict the output power of solar PV module in each area, which is shown in Figure 5.

It is assumed that the charging efficiency of battery is $90 \%$, the working efficiency of inverter is $80 \%$.The relationship between electricity generation and electricity consumption in every area is shown in Figure 6. The performance analysis results show output power of offgrid home photovoltaic power system is more than power consumption of TV and lamp. The configuration can meet the basic life demand of power to the people who power is not available.

\section{Conclusions}

The regional difference of solar energy resources distribution and temperature is big in Shaanxi as well as latitude difference. All of these are mainly influence factors of the performance of photovoltaic power generation system. Through the researches we can draw the conclusions:

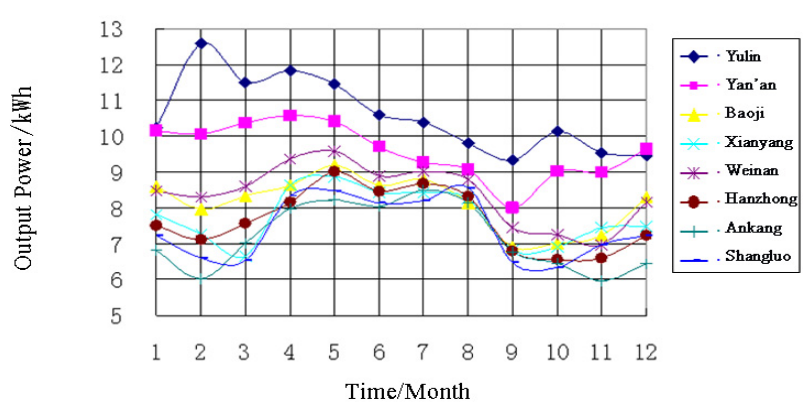

Figure 4. Output power of 100 Wp PV component.

Table 1. Type configuration.

\begin{tabular}{ccccc}
\hline No & Region & PV & Inverter & Battery \\
\hline 1 & Yulin & $135 \mathrm{Wp}$ & $300 \mathrm{VA}$ & $24 \mathrm{~V} 65 \mathrm{Ah}$ \\
2 & Yan'an & $170 \mathrm{Wp}$ & $300 \mathrm{VA}$ & $24 \mathrm{~V} 65 \mathrm{Ah}$ \\
3 & Weinan & $170 \mathrm{Wp}$ & $300 \mathrm{VA}$ & $24 \mathrm{~V} 65 \mathrm{Ah}$ \\
4 & Baoji & $180 \mathrm{Wp}$ & $300 \mathrm{VA}$ & $24 \mathrm{~V} 65 \mathrm{Ah}$ \\
5 & Xianyang & $180 \mathrm{Wp}$ & $300 \mathrm{VA}$ & $24 \mathrm{~V} 65 \mathrm{Ah}$ \\
6 & Hanzhong & $180 \mathrm{Wp}$ & $300 \mathrm{VA}$ & $24 \mathrm{~V} 80 \mathrm{Ah}$ \\
7 & Shangluo & $180 \mathrm{Wp}$ & $300 \mathrm{VA}$ & $24 \mathrm{~V} 80 \mathrm{Ah}$ \\
8 & Ankang & $180 \mathrm{Wp}$ & $300 \mathrm{VA}$ & $24 \mathrm{~V} 80 \mathrm{Ah}$ \\
\hline
\end{tabular}

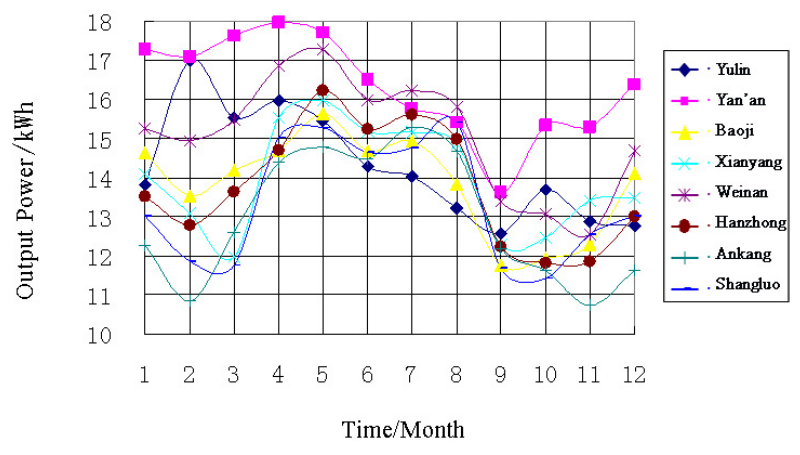

Figure 5. PV module output power prediction.

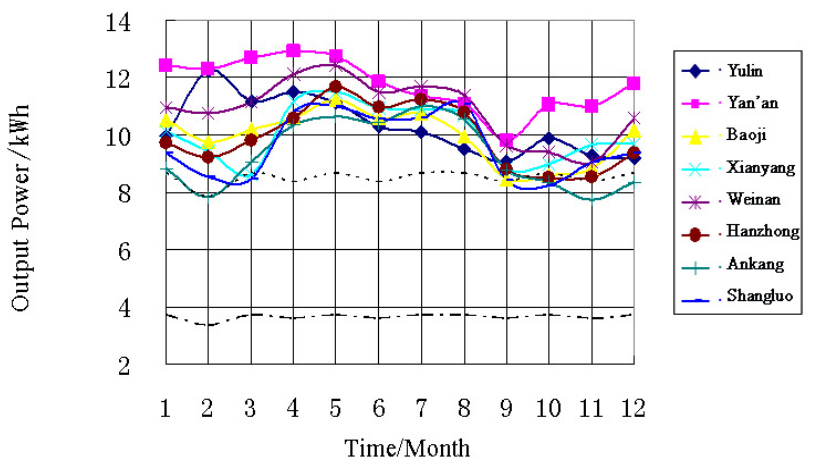

Figure 6. Output power prediction of off-grid home photovoltaic power system.

1) The output power of PV modules varies a lot in different areas of Shaanxi. It is mainly affected by the solar energy resources. The output power reaches to the largest in Shaanxi northern region, and the minimum occurs in Shaanxi southern region.

2) Because of the synthesis influence of solar resource and ambient temperature, output power in the winter is less than in the summer. It reaches the minimum in the spring and autumn.

3) According to the generating characteristics of PV modules in Shaanxi province, different types and configurations are selected in different areas systematically. The performance analysis shows that the configuration can meet the basic life demand of power to the people whose power is not available.

\section{REFERENCES}

[1] Divade, Z. R. Shi and H. Y. Lu, "The Pv-tech Application Study," Shanghai: Shanghai Jiaotong University Press, 2008.

[2] A. Li, "Solar Photovoltaic Systems Engineering,” Beijing: Beijing Industrial University Press, 2001.

[3] L. R. Wu, Z. H. Jiang, Y. P. Lu, J. W. Du, L. Qiao and H. J. Liu, "Space Distribution Evolution Characteristics of Sunshine Duration and Percentage in Shaanxi Province," Xian: Shaanxi Meteorological. 2008.1. 